\title{
HLA-A and -B alleles and haplotypes in 240 index patients with common variable immunodeficiency and selective IgG subclass deficiency in central Alabama
} James C Barton* ${ }^{* 1,2,3}$, Luigi F Bertoli ${ }^{\dagger 1,3}$ and Ronald T Acton ${ }^{\dagger 2,4}$

\begin{abstract}
Address: ${ }^{1}$ Southern Iron Disorders Center, Birmingham, Alabama, USA, ${ }^{2}$ Department of Medicine, University of Alabama at Birmingham, Birmingham, Alabama, USA, ${ }^{3}$ Department of Medicine, Brookwood Medical Center, Birmingham, Alabama, USA and ${ }^{4}$ Immunogenetics Program, Department of Microbiology, and Department of Epidemiology and International Health, University of Alabama at Birmingham, Birmingham, Alabama USA

Email: James C Barton* - ironmd@dnamail.com; Luigi F Bertoli - luigibertoli@dnamail.com; Ronald T Acton - acton@uab.edu

* Corresponding author †Equal contributors
\end{abstract}

Published: 12 June 2003

BMC Medical Genetics 2003, 4:3
Received: 01 March 2003

Accepted: 12 June 2003

This article is available from: http://www.biomedcentral.com/I47I-2350/4/3

(C) 2003 Barton et al; licensee BioMed Central Ltd. This is an Open Access article: verbatim copying and redistribution of this article are permitted in all media for any purpose, provided this notice is preserved along with the article's original URL.

\begin{abstract}
Background: We wanted to quantify HLA-A and -B phenotype and haplotype frequencies in Alabama index patients with common variable immunodeficiency (CVID) and selective IgG subclass deficiency (IgGSD), and in control subjects.
\end{abstract}

Methods: Phenotypes were detected using DNA-based typing (index cases) and microlymphocytotoxicity typing (controls).

Results: A and B phenotypes were determined in 240 index cases (II4 CVID, 126 IgGSD) and I,32I controls and haplotypes in 195 index cases and $75 \mathrm{I}$ controls. Phenotyping revealed that the "uncorrected" frequencies of $A * 24, B * 14, B * 15, B * 35, B * 40, B * 49$, and $B * 50$ were significantly greater in index cases, and frequencies of $B * 35, B * 58, B * 62$ were significantly lower in index cases. After Bonferroni corrections, the frequencies of phenotypes $A * 24, B * 14$, and $B * 40$ were significantly greater in index cases, and the frequency of $B * 62$ was significantly lower in index cases. The most common haplotypes in index cases were $A^{*} 02-B^{*} 44$ (frequency 0.1385 ), $A^{*} 01-B^{*} 08$ (frequency 0.1308 ), and $A * 03-B^{*} 07$ (frequency 0.1000 ), and the frequency of each was significantly greater in index cases than in control subjects ("uncorrected" values of $p<0.0001,0.0252$, and $0.001 \mathrm{I}$, respectively). After performing Bonferroni corrections, however, the frequency of $A * 02$ $B * 44$ alone was significantly increased in probands $(P<0.0085)$. Three other haplotypes were also significantly more frequent in index cases $\left(A * 03-B^{*} 14, A^{*} 31-B^{*} 40\right.$, and $\left.A * 32-B * 14\right)$. The combined frequencies of three latter haplotypes in index patients and control subjects were $0.04 \mathrm{II}$ and 0.0126 , respectively ("uncorrected" value of $p<0.0002$; "corrected" value of $p=0.0166$ ). Most phenotype and haplotype frequencies in CVID and IgGSD were similar. $26.7 \%$ of index patients were HLA-haploidentical with one or more other index patients. We diagnosed CVID or IgGSD in first-degree or other relatives of 26 of 195 index patients for whom HLA-A and -B haplotypes had been ascertained; $A * 0 I-B * 08, A * 02-B * 44$, and $A * 29-B * 44$ were most frequently associated with CVID or IgGSD in these families. We conservatively estimated the combined population 
frequency of CVID and IgGSD to be 0.0092 in adults, based on the occurrence of CVID and IgGSD in spouses of the index cases.

Conclusions: CVID and IgGSD in adults are significantly associated with several HLA haplotypes, many of which are also common in the Alabama Caucasian population. Immunoglobulin phenotype variability demonstrated in index cases and family studies herein suggests that there are multiple gene(s) on Ch6p or other chromosomes that modify immunoglobulin phenotypes of CVID and IgGSD. The estimated prevalence of CVID and IgGSD in central Alabama could be reasonably attributed to the fact that many HLA haplotypes significantly associated with these disorders are also common in the general population.

\section{Background}

Common variable immunodeficiency (CVID) and selective immunoglobulin G subclass deficiency (IgGSD) are characterized by subnormal serum concentrations of total IgG, or by normal serum total IgG concentrations with deficiency of one or more IgG subclasses, respectively; in some cases, IgA or IgM levels are also subnormal [1-3]. Most persons are diagnosed to have CVID or IgGSD because they have increased frequency and severity of infections due to bacteria and other microbial pathogens $[1,4]$. Although a susceptibility locus for these disorders has not been identified, they often appear to be familial and to segregate with markers on Ch6p $[1,5,6]$.

The purpose of the present work was to quantify and analyze the frequencies of HLA-A and -B phenotypes and haplotypes in index cases with CVID and IgGSD in central Alabama who presented because they had increased frequency or severity of infections, and to compare the present results to those of control subjects in this geographic area. We also evaluated the relationships of HLA$A$ and -B phenotype frequencies and haplotypes with phenotypes defined by serum immunoglobulin concentrations, and we estimated the combined frequency of CVID and IgGSD in central Alabama based upon the occurrence of these disorders in the spouses of the present index cases. The implications of the present results in determining the hereditary basis and immunoglobulin phenotype expression of CVID and IgGSD are discussed.

\section{Methods \\ Selection of Subjects}

General Criteria for Selection of Study Subjects

The performance of this work was approved by the Institutional Review Boards of Brookwood Medical Center and the University of Alabama at Birmingham, and the Ethical Principles for Medical Research involving Human Subjects promulgated by the World Medical Association Declaration of Helsinki were followed. All subjects were adults ( $\geq 18$ years of age) who identified themselves as Caucasians; each resided in central Alabama. The first persons in respective families diagnosed to have CVID or IgGSD were designated as index cases. All index persons were diagnosed in routine medical care in a single community medical center; none was diagnosed as a consequence of family or population screening. We included all evaluable index patients diagnosed between November 1991 and June 2002.

\section{CVID and IgGSD Index Cases}

Each patient was diagnosed to have CVID or IgGSD deficiency as an adult because he/she had frequent or unusually severe infections. Each patient had a single, severe or life-threatening infection that required hospitalization or four or more infections per year that required antibiotic therapy for at least two consecutive years. None was known to have pre-existing isolated IgA deficiency or other abnormality of immunity. Diagnoses were based on demonstration of persistent, otherwise unexplained serum concentrations of immunoglobulins $>2$ S.D. below the corresponding mean levels [1]. Criteria for the diagnosis of CVID were: 1) decreased total serum IgG concentration; and 2) either decreased IgG subclass(es), decreased serum IgA concentration, or decreased serum IgM concentration [1]. Criteria for the diagnosis of IgGSD were: 1) normal total serum IgG concentration; and 2) abnormally low serum concentrations of one or more IgG subclasses; some patients with IgGSD also had decreased levels of IgA or IgM levels [1].

We excluded persons of African American descent because: 1) certain HLA types and haplotypes differ significantly among Caucasians and African Americans in central Alabama [7-10]; 2) in adults, serum concentrations of immunoglobulins are often greater in persons of subSaharan African descent than in whites [11,12]; and 3) persons of sub-Saharan descent occur infrequently in series of CVID or IgGSD patients [4], and such patients are uncommon in our experience. We also excluded persons who had isolated deficiencies of IgA or IgM, those with hypogammaglobulinemia attributable to B-cell neoplasms (e.g., B-chronic lymphocytic leukemia, plasma cell myeloma, macroglobulinemia, or non-Hodgkin's lymphoma) or those with markedly increased immunoglobulin loss (e.g., nephrotic syndrome or protein-losing enteropathy). 


\section{Control Subjects}

Data from 1,321 apparently normal, unrelated Caucasian adult subjects from Alabama who had undergone HLA-A and -B phenotype analysis as part of paternity testing were used to estimate allele and gene frequencies [10,13]. HLA$A$ and -B haplotypes were determined in 751 unrelated Caucasian subjects from Alabama who had undergone testing to establish paternity [10]. Haplotypes were assessed from a child and his/her mother or father, and included in the data set. Preliminary data analysis revealed that frequencies of the major HLA-A and -B haplotypes observed in the present control subjects were similar to those estimated to occur in Caucasians from a large national bone marrow donor program [14].

\section{Family Members}

We diagnosed CVID or IgGSD deficiency in some family members using the same criteria defined herein for index patients. These persons presented themselves for evaluation after an index case was diagnosed in their respective kinships because they also had increased frequency and severity of bacterial infections. Although other relatives of index cases were also reported to have increased frequency and severity of infections or to have some form of antibody deficiency, they were not included in the present study because we did not evaluate them. Screening or other systematic testing of family members of the present index cases was beyond the scope of the present study.

\section{Laboratory Methods}

Serum concentrations of IgG, IgA, IgM, and IgG subclasses were measured using standard automated methods before IgG replacement therapy was initiated. Reference ranges for serum immunoglobulin concentrations are: total IgG 700 - $1600 \mathrm{mg} / \mathrm{dL} ; \mathrm{IgG}_{1} 422$ - $1292 \mathrm{mg} / \mathrm{dL} ; \mathrm{IgG}_{2} 117$ $747 \mathrm{mg} / \mathrm{dL} ; \mathrm{IgG}_{3} 41$ - $129 \mathrm{mg} / \mathrm{dL} ; \mathrm{IgG}_{4} 1-291 \mathrm{mg} / \mathrm{dL}$; total IgA 70 - $400 \mathrm{mg} / \mathrm{dL}$; and IgM $40-230 \mathrm{mg} / \mathrm{dL}$. The basis of these reference ranges has been reported elsewhere [15]. Deficiency of an immunoglobulin class or subclass was defined by a serum concentration at diagnosis that was less than the corresponding lower reference limit. Measurement of IgA subclasses, IgD, or IgE in serum was not routinely performed.

HLA -A and -B alleles were detected using low-resolution DNA-based typing (PCR/sequence-specific oligonucleotide probe) in index cases [16]. Control subjects were tested using the microdroplet lymphocytotoxicity test [8]; subjects were evaluated using antisera that detected allele assignments described in the $9^{\text {th }}$ International Histocompatibility Workshop [17]. Because the levels of resolution of the DNA-based and serological typing methods we used are similar, alleles detected by these respective methods provide concordant allele assignments, with the exception of $\mathrm{B}^{*} 70$ and $\mathrm{B}^{*} 71$ that were not detected by serological methods. HLA typing of family members was performed to permit assignment of Ch6p haplotypes. In each index patient in whom a single A or B allele was detected by DNA-based typing, we verified the allele(s) and set phase to ascertain haplotypes of the index patient using HLA analyses of appropriate family members. For the present analysis, all haplotypes were defined only by $\mathrm{A}$ and $\mathrm{B}$ alleles.

\section{Statistical Considerations}

A data set that included HLA-A and -B phenotypes in 240 index patients with either CVID or IgGSD and HLA-A and -B haplotypes in 195 of these 240 index patients was available. Absolute or "uncorrected" values of A and B phenotype frequencies in index cases, $\mathrm{A}$ and $\mathrm{B}$ haplotype frequencies, and occurrence of two-haplotype combinations were calculated after enumeration of the raw data. To correct for the possible occurrence of spurious HLA antigen and haplotype associations due to multiple comparisons, we also computed values of $p$ using the Bonferroni inequality method [18]. "Corrected" values of $p$ are displayed in tabular form along with "uncorrected" values. A computer spreadsheet (Excel 2000, Microsoft Corp., Redmond, WA) and a statistical program (GB-Stat, v. 8.0 2000, Dynamic Microsystems, Inc., Silver Spring, $\mathrm{MD}$ ) were used to perform the present analyses. Means were compared using a student t-test (two-tail). Frequency values were compared using chi-square analysis or Fisher's exact test (one-tail), as appropriate. A value of $p<0.05$ was defined as significant. Only significant values of $p$ are displayed, and these are expressed to four significant figures.

\section{Results}

General Characteristics of CVID and IgGSD Index Patients There were approximately equal fractions of index patients with CVID and IgGSD, respectively (Table 1). There was a preponderance of women in index patients in both disorders. The mean ages of patients in CVID and IgGSD groups were similar. In CVID, the most frequent pattern of IgG deficiency was that of $\operatorname{IgG}_{1}+\operatorname{IgG}_{3}$ subclasses. In persons with IgGSD, isolated $\operatorname{IgG}_{3}$ deficiency was the most frequent IgG subclass deficiency phenotype (Table 1). Eight of the present index patients (3 CVID, 5 IgGSD; 2 men, 6 women) also had hemochromatosis associated with homozygosity for HFE C282Y on Ch6p; another man had CVID and a hemochromatosis phenotype associated with the HFE genotype C282Y/H63D.

\section{Frequencies of HLA-A and -B Phenotypes}

Sixteen A phenotypes were detected in 240 index cases and control subjects (Table 2). The most frequent A phenotypes in index cases were $A^{*} 02$ (0.5292), $A^{*} 01$ $(0.3458)$, and $A^{*} 03(0.2875)$. The most frequent $A$ phenotypes in controls were $A^{*} 02(0.5206), A^{*} 01$ (0.3397), and $A^{*} 03(0.2739)$. The phenotype $A^{*} 24$ occurred with 
Table I: Characteristics of Index Patients with CVID and IgGSD.'

\begin{tabular}{|c|c|c|}
\hline Characteristic & CVID $(n=114)$ & $\operatorname{lgGSD}(n=126)$ \\
\hline Men: Women & $32: 82$ & 38: 88 \\
\hline Age at Diagnosis, y (range) & $54 \pm 16(2 \mid-87)$ & $51 \pm 13(18-89)$ \\
\hline Serum Total lgG, mg/dL (range) & $527 \pm 115(140-697)$ & $953 \pm 199(700-|75|)$ \\
\hline Deficient IgG Subclass(es) & Percentage (n) & Percentage (n) \\
\hline 1,3 & $38.6(44)$ & $8.7(11)$ \\
\hline I & 16.7 (19) & $17.5(22)$ \\
\hline $\mathrm{I}, 2,3$ & $12.3(14)$ & 0 \\
\hline 3 & $7.0(8)$ & $52.4(66)$ \\
\hline 1,2 & $7.0(8)$ & 0 \\
\hline I, 3,4 & $7.0(8)$ & 0 \\
\hline 1,4 & $5.3(6)$ & $3.2(4)$ \\
\hline 2,3 & $3.5(4)$ & $1.6(2)$ \\
\hline $\mathrm{I}, 2,3,4$ & $2.6(3)$ & 0 \\
\hline 2 & $0.9(1)$ & $3.2(4)$ \\
\hline $1,2,4$ & $0.9(1)$ & 0 \\
\hline 4 & 0 & $7.9(10)$ \\
\hline 3,4 & 0 & $4.8(6)$ \\
\hline $2,3,4$ & 0 & $0.8(1)$ \\
\hline Index Patients with Serum IgA Deficiency, \% (n) & $21.1(24)$ & $9.5(12)$ \\
\hline Index Patients with Serum IgM Deficiency, \% (n) & $18.4(21)$ & $7.9(10)$ \\
\hline
\end{tabular}

I By definition, all probands with CVID had subnormal serum concentrations of total IgG at diagnosis; mean serum IgG concentrations were significantly lower in CVID $(p<0.000 .1$; two-tail t-test). The percentage of index patients with IgA deficiency was significantly greater in CVID ( $p=$ 0.0293; Chi-square test). The percentage of index patients with IgM deficiency was significantly greater in CVID ( $p=0.0156$; Chi-square test).

Table 2: Phenotype Frequencies of HLA-A Alleles in Alabama Subjects. ${ }^{1}$

\begin{tabular}{|c|c|c|c|c|}
\hline$A^{*}$ Phenotypes & $\begin{array}{l}\text { Frequency in CVID and IgGSD Index } \\
\text { Patients }(n=240)\end{array}$ & Frequency in Control Subjects (n) & $\begin{array}{l}\text { Significant Uncorrected } \\
\text { Values of } p\end{array}$ & $\begin{array}{l}\text { Significant Corrected } \\
\text { Values of } p^{2}\end{array}$ \\
\hline 01 & 0.3458 & $0.3397(1,319)$ & & \\
\hline 02 & 0.5292 & $0.5206(1,310)$ & & \\
\hline 03 & 0.2875 & $0.2739(1,318)$ & & \\
\hline 11 & 0.075 & $0.1136(1,320)$ & & \\
\hline 23 & 0.0500 & $0.0375(1,254)$ & & \\
\hline 24 & 0.300 & $0.1304(1,265)$ & $<0.0001$ & $<0.0016$ \\
\hline 25 & 0.0333 & $0.0297(I, 28 I)$ & & \\
\hline 26 & 0.0500 & $0.0634(1,278)$ & & \\
\hline 28 & 0.025 & $0.0773(1,320)$ & & \\
\hline 29 & 0.0583 & $0.0620(1,290)$ & & \\
\hline 30 & 0.0292 & $0.0405(1,308)$ & & \\
\hline 31 & 0.0542 & $0.0350(1,258)$ & & \\
\hline 32 & 0.0375 & $0.0536(1,232)$ & & \\
\hline 33 & 0.0083 & $0.0176(1,248)$ & & \\
\hline 34 & 0.0083 & $0.0044(1,146)$ & & \\
\hline 66 & 0.0167 & $0(243)$ & & \\
\hline
\end{tabular}

I Phenotypes were detected using low-resolution DNA-based typing in CVID and IgGSD index patients and microlymphocytotoxcity typing in control subjects. Because our HLA typing was conducted over a period of several years during which splits of certain alleles had not been defined, we collapsed the phenotype HLA-A*10 into HLA-A*26 and the phenotype HLA-A*68 into HLA-A*28 to facilitate the present comparisons. ${ }^{2}$ These values were corrected using the Bonferroni inequality method. 
Table 3: Phenotype Frequencies of HLA-B Alleles in Alabama Subjects.'

\begin{tabular}{|c|c|c|c|c|}
\hline B* Phenotypes & $\begin{array}{l}\text { Frequency in CVID and IgGSD Index } \\
\text { Patients }(n=240)\end{array}$ & $\begin{array}{l}\text { Frequency in Control } \\
\text { Subjects (n) }\end{array}$ & $\begin{array}{l}\text { Significant Uncorrected } \\
\text { Values of } p\end{array}$ & Significant Corrected Values of $p^{2}$ \\
\hline 07 & 0.2667 & $0.2259(1,321)$ & & \\
\hline 08 & 0.2583 & $0.2487(1,315)$ & & \\
\hline 13 & 0.0250 & $0.0343(1,3 \mid 4)$ & & \\
\hline 14 & 0.1167 & $0.0639(1,314)$ & 0.0037 & \\
\hline 15 & 0.0792 & $0.0144(1,320)$ & $<0.0001$ & $<0.0030$ \\
\hline 18 & 0.0708 & $0.0775(1,251)$ & & \\
\hline 27 & 0.0708 & $0.0895(1,318)$ & & \\
\hline 35 & 0.0917 & $0.1406(1,309)$ & 0.0403 & \\
\hline 37 & 0.0250 & $0.0240(1,167)$ & & \\
\hline 38 & 0.0167 & $0.0193(1,194)$ & & \\
\hline 39 & 0.0250 & $0.0225(1,198)$ & & \\
\hline 40 & 0.0792 & $0.0265(1,321)$ & $<0.0001$ & $<0.0030$ \\
\hline 41 & 0.0167 & $0.0119(1,089)$ & & \\
\hline 42 & 0.0042 & $0.0040(1,252)$ & & \\
\hline 44 & 0.3167 & $0.2866(1,263)$ & & \\
\hline 45 & 0.0083 & $0.0177(I, 24 I)$ & & \\
\hline 46 & 0.0042 & $0(19)$ & & \\
\hline 47 & 0.0083 & $0.0039(513)$ & & \\
\hline 48 & 0.0042 & 0 (909) & & \\
\hline 49 & 0.0417 & $0.0171(1,230)$ & 0.0153 & \\
\hline 50 & 0.0333 & $0.0140(1,212)$ & 0.0414 & \\
\hline 51 & 0.1042 & $0.0696(1,250)$ & & \\
\hline 52 & 0.0167 & $0.0180(1,164)$ & & \\
\hline 53 & 0.0083 & $0.0077(1,163)$ & & \\
\hline 54 & 0 & $0.0058(1,027$ & $-\cdots$ & \\
\hline 55 & 0.0208 & $0.0259(1,042)$ & & \\
\hline 56 & 0.0125 & $0.0097(928)$ & & \\
\hline 57 & 0.0667 & $0.0385(1,014)$ & & \\
\hline 58 & 0.0042 & $0.0256(1,014)$ & 0.0228 & \\
\hline 60 & 0.0583 & $0.1206(1,086)$ & & \\
\hline 61 & 0.0167 & $0.0173(980)$ & & \\
\hline 62 & 0.0333 & $0.1285(1,175)$ & $<0.0001$ & $<0.0030$ \\
\hline 78 & 0.0042 & no data & - . - & \\
\hline
\end{tabular}

I Phenotypes were detected using low-resolution DNA-based typing in CVID and IgGSD patients and microlymphocytotoxcity typing in control subjects. ${ }^{2}$ These values were corrected using the Bonferroni inequality method.

significantly greater frequency in index cases $(0.3000$ index cases vs. 0.1304 controls; $p<0.0001$ "uncorrected" and $p<0.0016$ "corrected"). There were no other significant differences in HLA-A phenotype frequencies between these groups (Table 2).

Thirty-two B phenotypes were detected in 240 index cases (Table 3). Thirty B phenotypes were detected in control subjects. The most frequent $\mathrm{B}$ phenotypes in index cases were $\mathrm{B}^{*} 44(0.3167), \mathrm{B}^{*} 07(0.2667)$, and $\mathrm{B}^{*} 08(0.2583)$. The most frequent $\mathrm{B}$ alleles in controls were $\mathrm{B}^{*} 44$ $(0.2866), B^{*} 08(0.2487)$, and $B^{*} 07(0.2259)$. The frequencies of $\mathrm{B}^{*} 14, \mathrm{~B}^{*} 15, \mathrm{~B}^{*} 35, \mathrm{~B}^{*} 40, \mathrm{~B}^{*} 49$, and $\mathrm{B}^{*} 50$ were significantly greater in index cases based on "uncorrected" values of $p$ (Table 3 ). The frequencies of $\mathrm{B}^{*} 14$ and $B * 40$ were significantly greater in index cases based on "corrected" values of $p$ (Table 3 ). The frequencies of $\mathrm{B}^{*} 58$ and $\mathrm{B}^{*} 62$ were significantly lower in index cases based on "uncorrected" values of $p$ (Table 3 ). The frequency of $B^{*} 62$ was significantly lower in index cases based on a "corrected" value of $p$ (Table 3 ).

\section{Frequencies of HLA-A and -B Haplotypes}

Data were available that permitted frequency comparisons to be made between index cases and probands for 85 haplotypes. The most frequent haplotypes in index cases were $\mathrm{A}^{*} 02-\mathrm{B}^{*} 44$ (frequency 0.1385 ), $\mathrm{A}^{*} 01-\mathrm{B}^{*} 08$ (frequency 0.1308 ), and $\mathrm{A}^{*} 03-\mathrm{B}^{*} 07$ (frequency 0.1000 ) (Table 4). Each of these haplotypes was significantly more frequent in index cases than in control subjects ("uncorrected" values of $p<0.0001,0.0252$, and 0.0011, respectively) (Table 4). After performing the Bonferroni corrections, the frequency of $\mathrm{A}^{*} 02-\mathrm{B}^{*} 44$ alone was significantly increased in probands $(p<0.0085)$ (Table 4$)$. 
Table 4: HLA-A and -B Haplotypes in Alabama Subjects.

\begin{tabular}{llllll}
\hline HLA-A & HLA-B & $\begin{array}{l}\text { Frequency in I95 CVID and IgGSD } \\
\text { Index Cases (390 chromosomes) }\end{array}$ & $\begin{array}{l}\text { Frequency in 75I Controls } \\
\text { (1502 chromosomes) }\end{array}$ & $\begin{array}{l}\text { Significant Uncorrected } \\
\text { Values of } p\end{array}$ & $\begin{array}{l}\text { Significant Corrected } \\
\text { Values of } p^{1}\end{array}$ \\
\hline 01 & 08 & 0.1308 & 0.0925 & 0.0252 & $<0.0085$ \\
02 & 44 & 0.1385 & 0.0633 & 0.0001 & \\
& 60 & 0.0103 & 0.0233 & 0.0076 & \\
03 & 07 & 0.1000 & 0.0546 & 0.0095 & \\
& 14 & 0.0231 & 0.0113 & 0.0122 & \\
31 & 44 & 0 & 0.0127 & 0.0187 & \\
32 & 40 & 0.0103 & 0.0013 & 0.0087 & \\
\hline
\end{tabular}

I These values were corrected using the Bonferroni inequality method.

Table 5: HLA Haploidentical Alabama Index Cases.'

\begin{tabular}{|c|c|c|}
\hline First Haplotype & Second Haplotype & Frequency of Haploidentical Index Cases (n) \\
\hline \multirow[t]{7}{*}{$A * 01-B * 08$} & $A * 02-B * 27$ & $0.0154(3)$ \\
\hline & $A * 02-B * 44$ & $0.0256(5)$ \\
\hline & $A * 03-B * 07$ & $0.0205(4)$ \\
\hline & $A * 23-B * 44$ & $0.0103(2)$ \\
\hline & $A * 29-B * 44$ & $0.0103(2)$ \\
\hline & $A * 30-B * 13$ & $0.0103(2)$ \\
\hline & $A * 32-B * 14$ & $0.0103(2)$ \\
\hline$A * 02-B * 07$ & $A * 03-B * 07$ & $0.0154(3)$ \\
\hline$A * 02-B * 18$ & $A * 02-B^{*} 44$ & $0.0103(2)$ \\
\hline \multirow[t]{6}{*}{$A * 02-B * 44$} & $A^{*} 02-B^{*} 44$ & $0.0205(4)$ \\
\hline & $A * 02-B * 60$ & $0.0103(2)$ \\
\hline & $A * 03-B * 07$ & $0.0205(4)$ \\
\hline & $A * 03-B * 14$ & $0.0103(2)$ \\
\hline & $A * 25-B * 18$ & $0.0103(2)$ \\
\hline & $A * 31-B * 40$ & $0.0103(2)$ \\
\hline \multirow[t]{3}{*}{$A * 03-B * 07$} & $A * 03-B * 07$ & $0.0103(2)$ \\
\hline & $A * 24-B * 44$ & $0.0103(2)$ \\
\hline & $A * 29-B * 44$ & $0.0154(3)$ \\
\hline$A * 24-B * 07$ & $A * 29-B * 18$ & $0.0103(2)$ \\
\hline$A * 24-B * 60$ & $A * 28-B * 60$ & $0.0103(2)$ \\
\hline
\end{tabular}

1 These two-haplotype matches were observed in 52 of 195 Caucasian index patients (26.7\%) with CVID or lgGSD (390 chromosomes) who resided in central Alabama. Frequencies are expressed as fractions of 195 index cases. Twenty-one patients representing nine different haplotype combination occured in CVID cases, seventeen patients representing six different haplotype combinations occurred in IgGSD cases, and another I4 patients representing seven different haplotype combinations occurred across the the two index patient groups. Evaluation of these data revealed that there were no significant differences in the freqencies of the various haplotypes in these groups of 52 CVID and IgGSD index cases.

Three other haplotypes were also significantly more frequent in index cases based on "uncorrected" values of $p$. These were $\mathrm{A}^{*} 03-\mathrm{B}^{*} 14, \mathrm{~A}^{*} 31-\mathrm{B} * 40$, and $\mathrm{A}^{*} 32-\mathrm{B}^{*} 14$ (Table 4). The combined frequencies of these three latter haplotypes were 0.0411 in index patients and 0.0126 in control subjects $(p<0.0002$ "uncorrected" and $p=0.0166$ "corrected"). Two haplotypes were significantly more frequent in control subjects based on "uncorrected " values of $p$. These were $A^{*} 02-B^{*} 60$ and $A^{*} 03-B^{*} 44$ (Table 4). However, these differences were no longer significant after correction using the Bonferroni method. Homozygosity for these haplotypes was observed in some index cases: $\mathrm{A}^{*} 02$ $\mathrm{B}^{*} 07(\mathrm{n}=1) ; \mathrm{A}^{*} 02-\mathrm{B}^{*} 44(\mathrm{n}=4) ; \mathrm{A}^{*} 02-\mathrm{B}^{*} 62(\mathrm{n}=1) ;$ and $A^{*} 03-B^{*} 07(n=2)$.

Fifty-two of 195 index patients (26.7\%) were HLA-haploidentical with at least one other index case in the present study (Table 5). Forty-eight of these 52 index patients $(92.3 \%)$ had the haplotypes $A^{*} 01-B^{*} 08, A^{*} 02-B^{*} 44$, or $\mathrm{A}^{*} 03-\mathrm{B}^{*} 07$. Altogether, eighteen different haplotypes defined by A and B typing were observed in these 52 index cases (Table 5). 


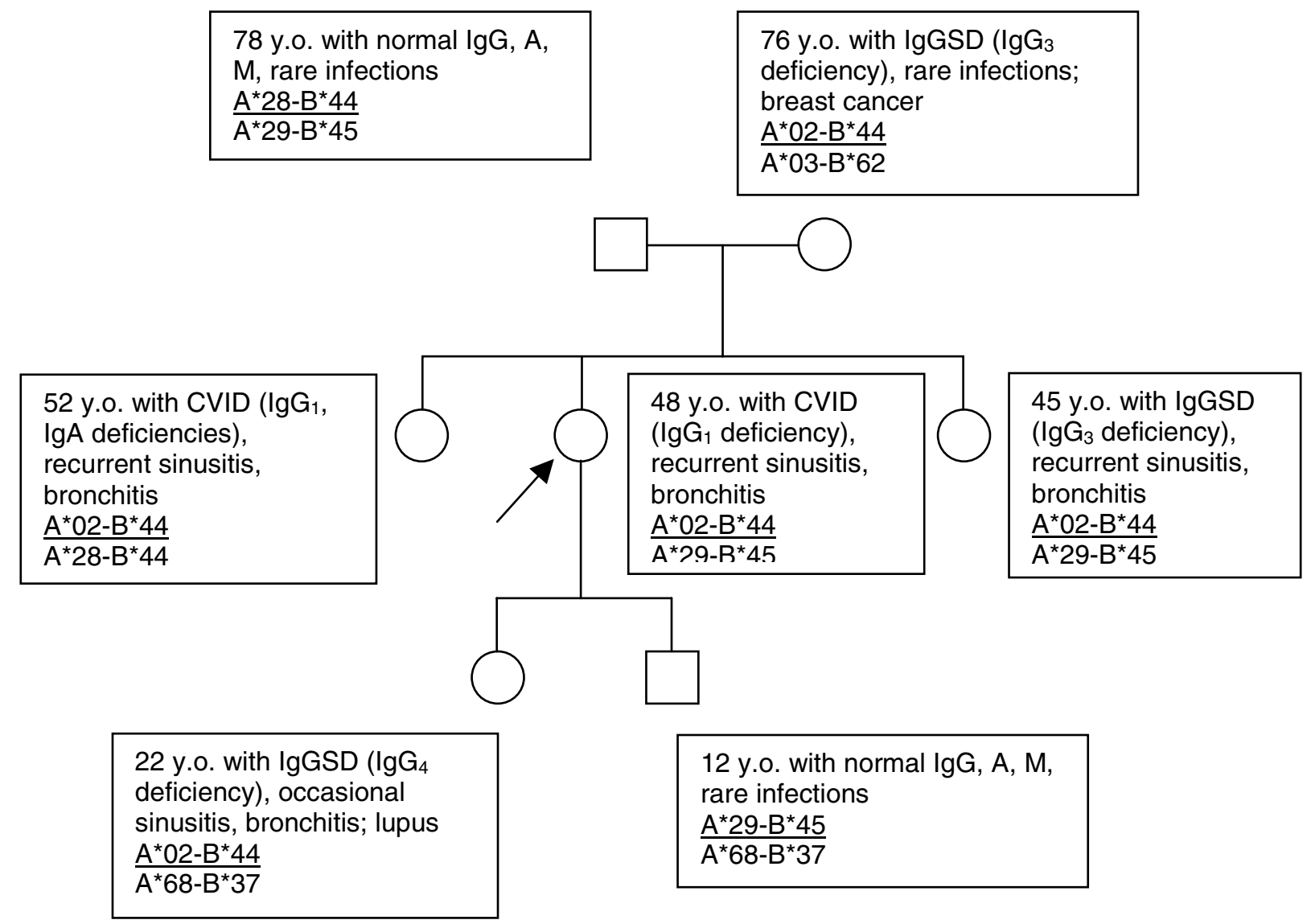

\section{Figure I}

Pedigree of kinship in which various antibody deficiency phenotypes occurred in association with inheritance of the HLA haplotype $A^{*} 02-B^{*} 44$. Index patient indicated by arrow. CVID = common variable immunodeficiency; IgGSD = selective lgG subclass deficiency.

\section{Segregation of HLA Haplotypes with CVID or IgGSD in Kinships}

We diagnosed CVID or IgGSD in first-degree or other relatives of 26 of 195 index patients for whom HLA-A and $B$ haplotypes had been ascertained. These haplotypes segregated with CVID or IgGSD in 24 of the 26 kinships: $\mathrm{A}^{*} 01-\mathrm{B}^{*} 08$ (10 kinships); $\mathrm{A}^{*} 02-\mathrm{B}^{*} 08$ (1 kinship); $\mathrm{A}^{*} 02$ $\mathrm{B}^{*} 44$ (8 kinships) (Fig. 1); $\mathrm{A}^{*} 02-\mathrm{B}^{*} 50$ (1 kinship); $\mathrm{A}^{*} 03$ $\mathrm{B}^{*} 07$ (1 kinship); $\mathrm{A}^{*} 11-\mathrm{B}^{*} 35$ (1 kinship); and $\mathrm{A}^{*} 29$ $\mathrm{B}^{*} 44$ ( 2 kinships). In one of the two remaining kinships, both $A^{*} 02-B^{*} 07$ and $A^{*} 03-B^{*} 07$ segregated with CVID or IgGSD (Fig 2.). In the other remaining kinship, one index patient and her sister had IgGSD but they were HLA-nonidentical. However, each of these women inherited a hap- lotype significantly associated with CVID and IgGSD (index patient $A^{*} 02-B^{*} 44$ and $A^{*} 03-B^{*} 57$; sister $A^{*} 03$ $B * 35$ and $A * 23-B * 27)$.

\section{Relationships of HLA Phenotypes and Haplotypes to Immunoglobulin Phenotypes \\ Comparison of HLA-A and -B Phenotype Frequencies in CVID and $\operatorname{lgGSD}$}

The frequencies of A phenotypes were similar in the CVID and IgGSD, with the exceptions that HLA-A*24 which occurred with significantly greater frequency in IgGSD cases ( 0.4206 vs. 0.1667 CVID, $p=<0.0001)$, and that HLA-A*31 was more frequent in CVID cases (0.0877 vs. 0.0238 IgGSD, $p=0.0277)$. The frequencies of HLA-B 


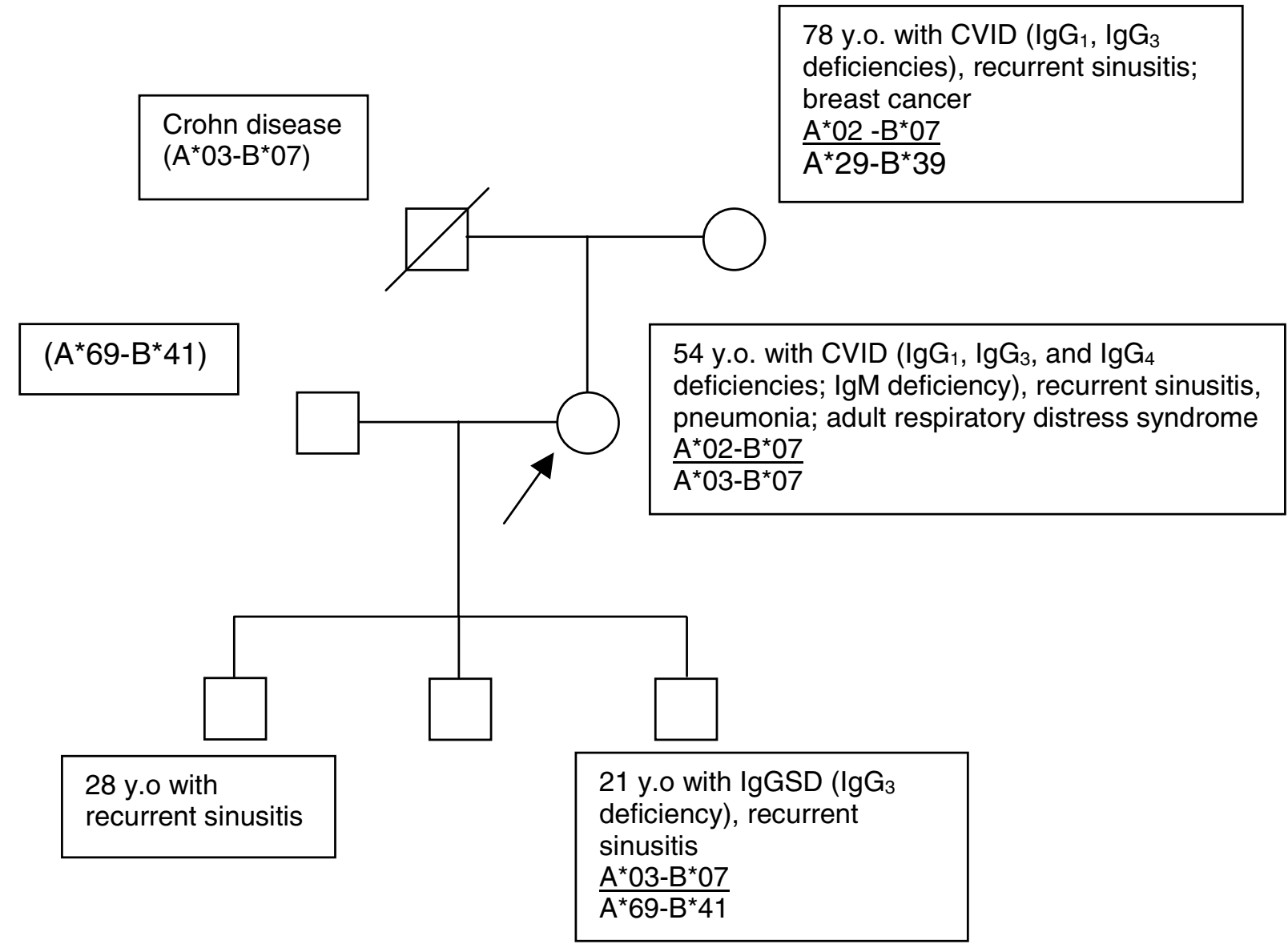

\section{Figure 2}

Pedigree of kinship in which various antibody deficiency phenotypes occurred in association with inheritance of the HLA haplotypes $A * 02-B * 07$ and $A * 03-B * 07$. Index patient indicated by arrow. Deduced haplotypes displayed in parentheses. CVID = common variable immunodeficiency; $\lg G S D$ = selective $\lg G$ subclass deficiency.

phenotypes were similar in the two groups, with the exceptions that $\mathrm{B}^{*} 07$ and $\mathrm{B}^{*} 50$ occurred with significantly greater frequencies in IgGSD cases $(0.3333$ vs. 0.1930 CVID, $p=0.0101$; and 0.0635 vs. $0, p=0.0052$, respectively), and that $\mathrm{B}^{*} 55$ occurred more frequently in CVID cases $(0.0439$ vs. 0 IgGSD, $p=0.0231)$.

Comparison of Haplotype Frequencies in CVID and IgGSD

The haplotype frequencies in CVID and IgGSD did not differ significantly, with two exceptions. The frequency of $A * 23-B * 44$ was significantly greater in CVID patients than in IgGSD patients ( 0.0263 vs. 0 , respectively, $p=0.0267)$. The frequency of $A^{*} 24-B^{*} 35$ was greater in patients with
IgGSD than in patients with CVID (0.0250 vs. 0 , respectively, $p=0.0346$ ).

\section{Possible Dose Effect of Haplotype on Total Serum Immunoglobulin} Concentrations

Eleven haplotypes occurred with significantly greater frequency in index patients with CVID and IgGSD than in control subjects (described above). Mean values of serum IgG, IgA, or IgM did not vary significantly according to the inheritance of 0,1 , or 2 of these eleven haplotypes (Table 6). Similarly, some index patients in each pattern of IgG subclass deficiency were positive for one or two of these eleven haplotypes, with the exception of the sole index 
Table 6: Serum Immunoglobulin Concentrations in Index Patients with Significantly Associated HLA-A and -B Haplotypes. ${ }^{1}$

\begin{tabular}{llll}
\hline Number of Significantly Associated Haplotypes & 0 & I & 2 \\
\hline Serum $\operatorname{lgG}, \mathrm{mg} / \mathrm{dL}(\mathrm{n})$ & $734 \pm 273(45)$ & $735 \pm 287(\mathrm{II})$ & $749 \pm 257(33)$ \\
Serum $\operatorname{lgA}, \mathrm{mg} / \mathrm{dL}(\mathrm{n})$ & $167 \pm 92(48)$ & $157 \pm 117(109)$ & $169 \pm 71(33)$ \\
Serum $\operatorname{lgM}, \mathrm{mg} / \mathrm{dL}(\mathrm{n})$ & $108 \pm 70(46)$ & $116 \pm 96(110)$ & $115 \pm 108(34)$ \\
\hline
\end{tabular}

I These data are expressed as mean \pm I SD. Significantly associated haplotypes were defined as those that occurred with significantly greater frequency in CVID and IgGSD index cases than in control subjects. These six haplotypes were: $A * 01-B^{*} 08, A^{*} 02-B^{*} 44, A^{*} 03-B^{*} 07, A^{*} 03-B^{*} \mid 4, A^{*} 31-$ $B^{*} 40$, and $A * 32-B^{*} 14$ (see Table 4). There were no significant differences in the mean values of $\lg G$, $\lg A$, or $\lg M$ in the index patients grouped by inheritance of significantly associated haplotypes.

Table 7: CVID and IgGSD Index Cases Positive for Haplotype A*0 I-B*08.

\begin{tabular}{|c|c|c|c|}
\hline Serum Immunoglobulin Concentrations & $\begin{array}{l}\text { Total IgG Concentration, frequency in } \\
195 \text { Index Cases (fraction) }\end{array}$ & $\begin{array}{l}\text { IgA Concentration, frequency in } 195 \\
\text { Index Cases (fraction) }\end{array}$ & $\begin{array}{l}\text { IgM Concentration, frequency in } 195 \\
\text { Index Cases (fraction) }\end{array}$ \\
\hline No Deficiency² & $0.23(23 / 100)$ & $0.24(39 / 162)$ & $0.24(41 / 169)$ \\
\hline Deficiency $^{2}$ & $0.27(26 / 95)$ & $0.30(10 / 33)$ & $0.31(8 / 26)$ \\
\hline
\end{tabular}

I Comparisons of positivity for HLA haplotype $A * 0 \mathrm{I}-\mathrm{B} * 08$ revealed no significant differences (Chi-square analysis) in index cases grouped by serum total $\operatorname{lgG}$, IgA, and IgM concentration, respectively. ${ }^{2}$ Deficiency of an immunoglobulin class was defined by a serum concentration at diagnosis that was less than the corresponding lower reference limit.

patient with deficiencies of $\operatorname{IgG}_{1}, \operatorname{IgG}_{2}$, and $\operatorname{IgG}_{4}$ who did not have any of these twelve haplotypes.

Frequencies of Index Patients with HLA Haplotype $A * 0 I-B * 08$ Some reports suggest that IgA deficiency segregates with a HLA haplotype(s) containing $\mathrm{A}^{*} 01, \mathrm{~B}^{*} 08$ in some families $[4-6,19,20]$. Thus, we analyzed the frequencies of the haplotype $\mathrm{A}^{*} 01-\mathrm{B}^{*} 08$ in the present index patients grouped according to presence of normal or subnormal pre-treatment serum concentrations of IgG, IgA, and IgM, respectively. Although frequencies of positivity for $A^{*} 01$ $\mathrm{B}^{*} 08$ were slightly greater in index patients who had deficiencies of IgG, IgA, or IgM, these differences were not significant (Table 7). There were insufficient numbers of index patients homozygous for $\mathrm{A}^{*} 01-\mathrm{B}^{*} 08$ to estimate the effect of homozygosity for this haplotype on serum immunoglobulin concentrations.

\section{Disparity of Immunoglobulin Phenotype in Family Members with Same HLA Haplotype}

In some kinships, different immunoglobulin deficiency phenotypes were observed among family members with CVID or IgGSD who shared HLA-A and -B haplotypes. One representative pedigree demonstrating these disparities between immunoglobulin phenotype, frequency of infections, and HLA haplotype is displayed in Figure 1. In a second kinship, two different haplotypes segregated with antibody deficiency, although the immunoglobulin deficiency pattern was different in each of three affected family members (Fig. 2). One pair of monozygotic twins was available for evaluation. The index patient had IgGSD (IgG 3 subclass deficiency; HLAA24, 25;- B15, 49) and recurrent upper and lower respiratory tract infections. Her twin had normal serum concentrations of total IgG, IgG subclasses, IgA, and IgM, and did not report increased frequency or severity of infections.

\section{Estimation of Population Frequency of CVID and IgGSD}

The occurrence of CVID and IgGSD in spouses of the present index cases permitted us to estimate the combined population frequency of CVID and IgGSD in adults. At the time of diagnosis, 217 of the present 240 index cases had spouses. Of these 217 spouses, we diagnosed CVID in one and IgGSD in another because they also had increased frequency and severity of bacterial infections, predominantly those of the upper and lower respiratory tracts. Thus, a conservative estimate of the combined frequencies of these disorders in adults in central Alabama is 0.0092 (2/ 217).

\section{Discussion}

The present observations demonstrate that CVID and IgGSD in Caucasian adults diagnosed in routine medical care delivery are significantly associated with HLA haplotypes on Ch6p. More than two-thirds of the present 195 index patients who were evaluable for haplotyping inherited one or two of the significantly associated haplotypes $\mathrm{A}^{*} 01-\mathrm{B}^{*} 08, \mathrm{~A}^{*} 02-\mathrm{B}^{*} 44, \mathrm{~A}^{*} 03-\mathrm{B}^{*} 07, \mathrm{~A}^{*} 03-\mathrm{B}^{*} 14, \mathrm{~A}^{*} 31-$ $\mathrm{B}^{*} 40$, and $\mathrm{A}^{*} 32-\mathrm{B}^{*} 14$. This indicates that a susceptibility locus (loci) for CVID and IgGSD occurs on multiple hap- 
lotypes defined by HLA-A and -B typing. Further, this implies that putative Ch6p alleles associated with CVID or IgGSD susceptibility occur on many HLA haplotypes that are common in Caucasians in central Alabama [10] and in Caucasians from a large national bone marrow donor program [14]. The present observations also confirm and extend the reports of association of HLA haplotype $\mathrm{A}^{*} 01$ $\mathrm{B}^{*} 08$ (or an extended haplotype containing $\mathrm{A}^{*} 01$ and $\left.\mathrm{B}^{*} 08\right)$ with heritable forms of immunoglobulin deficiency demonstrated in family-based analyses [3,6,1922]. It is likely that a candidate gene(s) for CVID or IgGSD exists in the HLA class II region, [6,19-23]. Because the class II region is closer to the HLA-B locus than to the HLA-A locus, it is plausible that candidate gene(s) for CVID or IgGSD in the class II region are in greater linkage disequilibrium with HLA-B than HLA-A. This is consistent with the aggregate observations on HLA-A and -B typing in the present study.

The present observations demonstrate that the frequencies of HLA-A and -B phenotypes and haplotypes were not significantly different in CVID and IgGSD index patients, with few exceptions. These observations could be explained by the occurrence of an HLA-linked allele that is necessary to cause either CVID or IgGSD, but is insufficient to induce a specific immunoglobulin deficiency phenotype. Alternatively, the variable immunoglobulin deficiency phenotypes presently classified as CVID and IgGSD are best explained by the co-inheritance of multiple alleles, each of which has an independent effect on the immunoglobulin deficiency phenotype. Regardless, the variability we observed in IgG, IgA, and IgM phenotypes in index patients and family members is best explained by the co-inheritance of multiple allele(s) that influence the immunoglobulin phenotype. This is consistent with evidence for the occurrence on Ch6p of multiple distinct susceptibility genes for patterns of immunoglobulin deficiency, some recessive and others dominant [20]. For example, at least two putative alleles associated with heritable IgA deficiency occur on Ch6p, and each is associated with a different major histocompatibility (MHC) region haplotype $[22,23]$, whereas a putative susceptibility locus on chromosome 18 is not a major contributor to selective IgA deficiency [24]. Allele(s) on chromosomes other than Ch6p may also influence the phenotypic expression of CVID and IgGSD in adults. The inheritance of certain polymorphisms of the mannose-binding lectin gene on Ch10 in persons with CVID are associated with earlier age of onset of manifestations of antibody deficiency and with increased risk of autoimmunity [25]. Altogether, these observations are consistent with the hypothesis that many common heritable antibody deficiency phenotypes collectively diagnosed as CVID or IgGSD are the result of the inheritance of multiple disease- predisposing alleles on Ch6p and possibly other chromosomes.

We have estimated that the prevalence of CVID and IgGSD in adults in central Alabama is 0.0092. This estimated prevalence could be reasonably attributed to the fact that many of the HLA haplotypes significantly associated with CVID and IgGSD are also common in the general population. This could also explain a) the inheritance of two significantly associated HLA haplotypes in many of the present index cases, including most of the index patients who were HLA-haploidentical with at least one other index patient; b) the disparate immunoglobulin deficiency phenotypes of multiple family members who inherited the same HLA haplotype; and c) the occurrence of disparate haplotypes in two sisters who had similar immunoglobulin phenotypes.

Some of the haplotypes significantly associated with CVID and IgGSD in the present study also occur with significantly increased frequencies in central Alabama Caucasian hemochromatosis probands with homozygosity for HFE C282Y on Ch6p [10]. These haplotypes are $\mathrm{A}^{*} 03-\mathrm{B}^{*} 07$ and $\mathrm{A}^{*} 03-\mathrm{B}^{*} 14$ [[10]; present study]. These observations imply that susceptibility alleles for CVID and IgGSD occur on haplotypes that sometimes include the HFE $\mathrm{C} 282 \mathrm{Y}$ allele. In addition, the haplotypes $\mathrm{A}^{*} 01-\mathrm{B}^{*} 08$ and $\mathrm{A}^{*} 02-\mathrm{B}^{*} 44$ significantly associated with CVID and IgGSD in the present study are common in both hemochromatosis probands homozygous for HFE C282Y and control subjects in Alabama [[10]; present study]. Taken together, these observations could explain the occurrence of CVID or IgGSD and hemochromatosis due to HFE $\mathrm{C} 282 \mathrm{Y}$ homozygosity in some of the present index patients [26] and account for the occurrence of IgA deficiency and hemochromatosis in different members of the same family [27].

\section{Conclusions}

CVID and IgGSD are significantly associated with the HLA haplotypes $A^{*} 01-B^{*} 08, A^{*} 02-B^{*} 44, A^{*} 03-B^{*} 07, A^{*} 03-$ $\mathrm{B}^{*} 14, \mathrm{~A}^{*} 31-\mathrm{B}^{*} 40$, and $\mathrm{A}^{*} 32-\mathrm{B}^{*} 14$. Many of these haplotypes are also common in the Alabama Caucasian population. Immunoglobulin phenotype variability demonstrated in index cases and in family studies suggest that there are multiple gene(s) on Ch6p or other chromosomes that modify the immunoglobulin phenotypes of CVID and IgGSD. The estimated prevalence of these disorders in central Alabama is 0.0092 . The estimated prevalence of CVID and IgGSD in central Alabama could be reasonably attributed to the fact that many HLA haplotypes significantly associated with these disorders are also common in the general population. 


\section{Competing Interests}

None declared.

\section{Authors' contributions}

Author 1 (JCB) conceived the study, and contributed CVID and IgGSD index cases, case characterization, and HLA typing, tabulated index case HLA frequency values, performed statistical comparisons, and formulated the manuscript. Author 2 (LFB) contributed CVID and IgGSD index cases, case characterization, and HLA typing. Author 3 (RTA) contributed control subjects, their characterization, and control HLA typing, performed statistical comparisons, and edited the manuscript. All authors read and approved the final manuscript.

\section{Acknowledgments}

This work was supported in part by Southern Iron Disorders Center and Immunogenetics Program.

\section{References}

I. World Health Organization: Primary immunodeficiency diseases. Report of a WHO Scientific Group Immunodeficiency Reviews 1992, 3:195-236.

2. Espanol T, Catala M, Hernandez M, Caragol I and Bertran JM: Development of a common variable immunodeficiency in IgAdeficient patients Clin Immunol Immunopathol I 996, 80:333-335.

3. Carvalho Neves Forte W, Ferreira De Carvalho F, Damaceno N, Vidal Perez F, Gonzales Lopes C and Mastroti RA: Evolution of IgA deficiency to IgG subclass deficiency and common variable deficiency Allergol Immunopathol 2000, 28:18-20.

4. Cunningham-Rundles $C$ and Bodian $C$ : Common variable immunodeficiency: clinical and immunological features of 248 patients Clin Immunol 1999, 92:34-48.

5. Vorechovsky I, Litzman J, Lokaj J and Sobotkova R: Family studies in common variable immunodeficiency J Hyg Epidemiol Microbiol Immunol 1991, 35: 17-26.

6. Schroeder $\mathrm{HL} J \mathrm{r}$, Zhu ZB, March RE, Campbell RD, Berney SM, Nedospasov SA, Turetskaya RL, Atkinson TP, Go RC, Cooper MD and Volanakis JE: Susceptibility locus for IgA deficiency and common variable immunodeficiency in the HLA-DR3, -B8, Al haplotypes Mol Med 1998, 4:72-86.

7. Acton RT, Harman L, Go RC, Tseng ML and Bias W: Comparison of HLA phenotypes among African Americans from Alabama, Maryland, and North Carolina Transplant Proc 1993, 25:2404-2407.

8. Murphy CC, Acton RT, Barger BO, Go RC, Kirk KA, Reitnauer PJ and Roseman JM: Population genetic analysis of insulin dependent diabetes mellitus using HLA allele frequencies Clin Genet 1983, 23:405-4I4.

9. Barton JC, Edwards CQ, Bertoli LF, Shroyer TW and Hudson SL: Iron overload in African Americans Am J Med 1995, 99:616-623.

10. Barton JC and Acton RT: HLA-A and -B alleles and haplotypes in hemochromatosis probands with HFE C282Y homozygosity in Alabama BMC Medical Genetics 2002, 3:9.

1I. Shulman G, Gilich GC and Andrew MJ: Serum immunoglobulins $G, A$, and $M$ in White and Black Adults on the Witwatersrand S Afr Med J 1975, 49: I 160-I I64.

12. Lewis M, Miyashiro M, Huton J, Miller L and Sperber K: Immunoglobulin and IgG subclass levels in the African American and Hispanic populations of east Harlem Mt Sinai J Med 1998, 65:139- 145.

13. Barton JC, Harmon L, Rivers C and Acton RT: Hemochromatosis: association of severity of iron overload with genetic markers Blood Cells Mol Dis 1996, 22: 195-204.

14. Boucher K, Mori M, Milford E and Beatty PG: Estimation of HLAA, -B, -DR haplotype frequencies in five racial groups represented in the NMDP donor file In HLA 1998 Edited by: Gjertson DW, Terasaki PI. Lenexa: American Society for Histocompatibility and Immunogenetics;; 1998:57-78.
15. Dati F, Schumann G, Thomas L, Agnazi F, Baudner S, Bienvenu J, Blaagjerg O, Blirup-Jensen S, Carlström A, Hyloft-Petersen P, Johnson AM, Milford-Ward A, Ritchie RF, Svendsen PJ and Whicher J: Consensus of a group of professional societies and diagnostic companies on guidelines for interim reference range for 14 proteins in serum based on the standardization against the IFCC/BCR/CAP reference material (CRM 470) Eur J Clin Chem Clin Biochem 1996, 34:517-520.

16. Barton JC, Shih WWH, Sawada-Hirai R, Acton RT, Harman L, Rivers $C$ and Rothenberg BE: Genetic and clinical description of hemochromatosis probands and heterozygotes: evidence that multiple genes linked to the major histocompatibility complex are responsible for hemochromatosis Blood Cells Mol Dis 1997, 23:135-145.

17. Albert ED, Baur MP and Mayr WR: Histocompatibility Testing 1984 Berlin:Springer-Verlag; 1984

18. Tiwari JL and Terasaki PI: The Data and Statistical Analysis In HLA and Disease Association New York: Springer-Verlag; 1985:20.

19. Price P, Witt C, Allcock R, Sayer D, Garlepp M, Kok CC, French M, Mallal $S$ and Christiansen F: The genetic basis for the association of the 8.I ancestral haplotype (AI, B8, DR3) with multiple immunopathological diseases Immunol Rev 1999, 167:257-274.

20. Alper CA, Marcus-Bagley D, Awdeh Z, Kruskal MSI, Eisenbarth GS, Brink SJ, Katz AJ, Stein R, Bing DH, Yunis EJ and Schur PH: Prospective analysis suggests susceptibility genes for deficiencies of IgA and several other immunoglobulins on the [HLA-B8, SCOI, DR3] conserved extended haplotype Tissue Antigens 2000, 56:207-216.

2I. Vorechovský I, Zetterquist H, Paganelli R, Koskinen S, Webster AD, Björkander J, Smith Cl and Hammarström L: Family and linkage study of selective IgA deficiency and common variable immunodeficiency Clin Immunol Immunopathol 1995, 77: I85-192.

22. De la Concha EG, Fernandez-Arquero M, Gual L, Vigil P, Martinez A, Urcelay E, Ferreira A, Garcia-Rodriguez MC and Fontan GC: MHC susceptibility genes to IgA deficiency are located in different regions on different HLA haplotypes J Immunol 2002, 169:46374643.

23. Vorechovský I, Cullen M, Carrington M, Hammarström $L$ and Webster ADB: Fine mapping of IGADI in IgA deficiency and common variable immun odeficiency: identification and characterization of haplotypes shared by affected members of 10 I multiple-case families J Immunol 2000, 164:4408-44I6.

24. Vorechovský I, Blennow E, Nordenskjöld M, Webster AD and Hammarström $L$ : A putative susceptibility locus on chromosome 18 is not a major contributor to human selective IgA deficiency: evidence from meiotic mapping of 83 multiple-case families J Immunol 1999, 163:2236-2242.

25. Mullighan CG, Marshall SE and Welsh KI: Mannose binding lectin polymorphisms are associated with early age of disease onset and autoimmunity in common variable immunodeficiency Scand J Immunol 2000, 5 I: I I I-I 22.

26. Barton JC, Acton RT and Bertoli LF: Hemochromatosis and primary antibody deficiency: occurrence in the same individual and frequency of common HFE mutations among common variable immunodeficiency and IgG subclass deficiency index cases Blood 2000, 96:4b.

27. Joske RA and Traub M: Haemochromatosis, active chronic hepatitis, and familial IgA deficiency Digestion 1975, 12:32-38.

\section{Pre-publication history}

The pre-publication history for this paper can be accessed here:

http://www.biomedcentral.com/1471-2350/4/3/prepub 